\title{
IR-780 BASED-NANOPARTICLE CYTOTOXIC EFFECT ON MURINE BREAST CANCER CELLS (EHRLICH)
}

André Luiz Silva Oliveira',2*, Nicholas Zufelato³, Letícia Reis Silva², Andris Figueiroa Bakuzis ${ }^{3}$ Elisângela de Paula Silveira-Lacerda²

'Bolsista FAPEG, Programa de Pós-Graduação em Ciências Biológicas, Instituto de Ciências Biológicas(ICB), Universidade Federal de Goiás (UFG) - Goiânia (GO), Brazil.

2Laboratório de Genética Molecular e Citogenética, ICB/UFG - Goiânia (GO), Brazil.

${ }^{3}$ Laboratório Ressonância Ferromagnética e Nanomagnetismo, IF/UFG - Goiânia (GO), Brazil.

*Corresponding author: andreluiz@ufg.br

Objectives: The aim of this study was to evaluate the cells viability of the murine breast cancer cells (Ehrlich) after treatment with magnetic nanocarriers (MALBIR). Methodology: Ehrlich's ascites carcinoma cells were aspirated from the peritoneal cavity of the animals and washed with $1 \mathrm{x}$ PBS solution, and then maintained in a humidified atmosphere for $24 \mathrm{~h}$ at $37^{\circ} \mathrm{C}$ in $5 \% \mathrm{CO}_{2}$. RPMI-1640 medium was supplemented with $10 \% \mathrm{FBS}, 1 \%$ penicillin/streptomycin and $0.3 \%$ amphotericin. The MALBIR was used as treatment for $24 \mathrm{~h}$, which consist of ferrite-based magnetic nanoparticles, bovine albumin proteins and IR-780 iodide molecules, forming an aggregate nanostructure with a diameter around 100nm. Because IR-780 is cytotoxic, all concentration used $(0.0 ; 0.437 ; 0.875 ; 1.75 ; 3.5 ; 7 ; 14)$ were based in quantity of the IR-780 $\left(\mu \mathrm{g} \cdot \mathrm{mL}^{-1}\right)$ present in nanocarrier. The MALBIR cytotoxic effects were evaluated using the MTT assay with Ehrlich tumor cells as described by Mosman (1983). The results as presented as mean \pm SD obtained from three independent experiments each done in four replicates. Statistical significance was considered at $\mathrm{p}<0.05$ performed by one-way ANOVA with Tukey post test. The IC50 (IR-780 concentration in nanocarrier that results in a 50\% reduction in cellular viability) was acquired by dose-response curves (nonlinear regression curves from sigmoidal dose-response) using GraphPad Prism 5 for Windows. Results: The IR-780 present in MALBIR has a statistical significantly effect inducing cell death in a dose dependent manner on Ehrlich cells. At concentrations of 3.5, 7 and $14 \mu \mathrm{g} \cdot \mathrm{mL}^{-1}$ obtained a significantly different result from negative control with $\mathrm{p}<0.001$. By nonlinear regression curve was estimated an IC50 value on Ehlich cells of $14.2 \pm 1.7 \mu \mathrm{g} \cdot \mathrm{mL}^{-1}$. Similar results had previously been found for Sarcoma-180 tumor cell line and L-929 normal cell line treated with this same nanocarrier. Conclusions: In summary, MALBIR treatment has significant cytotoxic activity on Ehrlich cells line when compared to the reference negative control. Thus, these results suggest that the MALBIR treatment may share a distinct and important dose-dependent biological property. Additional studies are needed to compare normal cell line, determine the molecular mechanisms and to evaluate the potential in vivo anticancer activity of the MALBIR. Nevertheless, the nanocarrier shows potential for synergetic effect between the chemotherapeutic agent IR-780 and the nanoparticles, if magnetic hyperthermia treatment is also performed, that could decrease even further the IC50 of the nanoparticle. 